\title{
Anthropometric Relation of Neck and Waist Circumference in Overweight and Obese Nigerian Subjects: Implication for the Fashion Industry.
}

\author{
Loveday. E Oghenemavwe', Clinton S.D Orupabo ${ }^{2}$, Zudonu O. Onisoman ${ }^{1}$ \\ 'Department of Anatomy, Faculty of Basic Medical Sciences, College of Health Sciences, University of Port Harcourt, ${ }^{2}$ Department of Anatomy, Faculty of \\ Basic Medical Sciences, College of Medical Sciences, Rivers State University.
}

\section{Abstract}

\begin{abstract}
Introduction: In the local tailoring industries in Nigeria, it is generally assumed that the waist circumference is twice the neck circumference. Whether this is true for obese and overweight people is unknown. Objective: This study investigated the anthropometric relationship of the neck circumference to the waist circumference in overweight and obese people and its use in the clothing industry. Subjects and Methods: A sample size of 557 volunteers between 18 to 50 years was recruited for the study from the three campuses of the University of Port Harcourt. 391 were overweight (males=218, females=173) and 166 were obese (males=63, females=103). The neck and waist circumferences of volunteers were taken at the upper neck circumference (UNC), middle neck circumference (MNC), lower neck circumference (LNC) and upper waist circumference (UWC), middle waist circumference (MWC) and lower waist circumference (LWC) respectively. The Body Mass Index of the participants were determined after their weights and heights were measured to enable us categorize them into overweight and obese. The data obtained were analyzed with the aid of Microsoft Excel statistical tools. Results: Overweight males had UNC $=37.83 \mathrm{~cm}, \mathrm{UWC}=83.69 \mathrm{~cm}, \mathrm{MNC}=37.72 \mathrm{~cm} ; \mathrm{MWC}=85.79 \mathrm{~cm}, \mathrm{LNC}=38.43 \mathrm{~cm}, \mathrm{LWC}=86.37 \mathrm{~cm}$. Overweight females had UNC $=33.64 \mathrm{~cm}, \mathrm{UWC}=78.02 \mathrm{~cm}, \mathrm{MNC}=33.64 \mathrm{~cm}, \mathrm{MWC}=83.09 \mathrm{~cm}, \mathrm{LNC}=34.71 \mathrm{~cm}, \mathrm{LWC}=83.09 \mathrm{~cm}$. Obese males had UNC $=40.15 \mathrm{~cm}, \mathrm{UWC}=93.87 \mathrm{~cm}, \mathrm{MNC}=40.12 \mathrm{~cm}, \mathrm{MWC}=97.95 \mathrm{~cm}, \mathrm{LNC}=40.85 \mathrm{~cm}, \mathrm{LWC}=97.82 \mathrm{~cm}$. Obese females had UNC $=35.07 \mathrm{~cm}$, $\mathrm{UWC}=90.86 \mathrm{~cm}, \mathrm{MNC}=35.29 \mathrm{~cm}, \mathrm{MWC}=97.29 \mathrm{~cm}, \mathrm{LNC}=36.01 \mathrm{~cm}, \mathrm{LWC}=100.72 \mathrm{~cm}$. Pearson's correlations $(\mathrm{r})$ of the different regions of the neck and waist for overweight and obese subjects were determined. Conclusion: The correlation between the neck and waist circumference is weak in both overweight and obese. No subject has a waist circumference that is exactly twice the neck circumference. Estimation of waist circumference from the neck circumference will result in clothes that are not fitted.
\end{abstract}

Keywords: Neck, waist, circumference, Overweight, Nigerians.

Corresponding Author: Dr. Clinton David Orupabo, Department of Anatomy, Faculty of Basic Medical Sciences, College of Medical Sciences, Rivers State University. P.M.B 5080, Nkpolu-Oroworokwu, Port Harcourt.

E mail: Clinton.orupabo@ust.edu.ng.

Received: March 2019

Accepted: April 2019

\section{Introduction}

Anthropometry has wide application in forensics, biological anthropology, clinical medicine, design of prosthetics and clothing as it tends to give predictive correlation between various body parts essential for diagnosis and design. We had earlier presented a paper on the anthropometric relationship of the neck circumference to waist circumference in non-obese subjects and its implication for the fashion industry. ${ }^{[1]}$ In similar manner, we find it necessary to evaluate overweight and obese subjects as the population of these group of persons are increasing by the day. Overweight is defined as body mass index (BMI) between 25 and $29.9 \mathrm{~kg} / \mathrm{m} 2$ while obesity is defined as BMI $\geq 30 \mathrm{~kg} / \mathrm{m} 2$. According to World Health Organization, WHO (2018), 1.9 billion adults, 18 years and older are overweight and 650 million of these figure are obese as at $2016 .{ }^{[2]}$ The trends of obesity have tripled worldwide since 1975. Overweight and obesity is not peculiar to adults but also common in adolescents and children, and over 340 million children and adolescents were overweight or obese in 2016. Clothing fashion like all other aspects of fashion changes very quickly. It is not associated with one group or an area of the world but is spread out throughout the world wherever people can communicate freely with one another. Getting body measurements is a significant part of sewing in the fashion industry as it would determine if the clothing would fit into the individual. Many body measurements with respect to the fashion industry include; neck, waist and hip measurements as well as other necessary parts of the body. Awareness of the correlations of these body parts is also essential in tailoring. These have resulted in the belief that the neck circumference is twice the waist circumference and 


\section{Oghenemawue et al; Anthropametric Relation of Neck and Waist Circumperence}

that fitness of clothes can be determined by using this correlation. Several authors have made good contributions in their studies with respect to the relationship between the neck and the waist circumference, and as a predictive measure to health and disease. ${ }^{[3-9]}$

In our previous study of Nigerians with normal weight, we found that the waist circumference is not exactly twice the neck circumference. However, there was a very strong positive correlation between the upper waist circumference and upper neck circumference. Whether this is applicable to overweight and obese individuals is not known as there are various types of distributions of body fat such as central obesity, gynaecoid obesity etc. Therefore the objective of the study is to determine what relationship exist between neck and waist circumferences and what part of the region of the neck and waist best correlate with one another in overweight and obese individuals. The information arising from this investigation would be of importance to fashion designers, aesthetic anatomists, and medical anthropologists and also provide quantitative information that will ensure a better customer service in the fashion industry.

\section{Subjects and Methods}

Simple random sampling method was used to recruit volunteers from the three campuses of the University of Port Harcourt. Individuals with physical deformities were excluded from the study. A sample size of 557 subjects participated in this study with age range of 18 to 50 years. 391 of them (218 males \& 173 females) were overweight, while 166 (63 males \& 103 females) were obese. All volunteers gave written informed consent before they participated in the study. The BMI of each subject was used to classify who is obese or overweight. Those with BMI $\geq$ $25-29.99 \mathrm{~kg} / \mathrm{m} 2$ were considered overweight and those with $\mathrm{BMI} \geq 30 \mathrm{~kg} / \mathrm{m} 2$ as obese. A weighing scale and stadiometer was used to determine the weight and height of the participants. The procedures for measurement were in line with standard anthropometric procedure recommended by World Health Organization. The neck circumference was measured with an inelastic measuring tape in three regionsthe upper part, just above the laryngeal prominence; the middle part, on the laryngeal prominence; and the lower part, below the laryngeal prominence. The waist circumference was taken at three parts- upper part, below the last rib and just above the umbilicus; the middle part, on the umbilicus; and the lower part, below the umbilicus. To ensure increase accuracy, all measurements were taken three times and the average recorded. The data was analyzed with the aid of Microsoft excel. Pearson's coefficient was used to determine its significance and correlation.

\section{Ethical Approval}

Ethical approval was sought from the College Research Ethics Committee, College of Health Sciences, University of Port Harcourt and was granted approval.

\section{Results}

Table 1: Neck and waist circumference based on sex for overweight subjects

\begin{tabular}{|l|l|l|l|l|l|}
\hline Parameter & Sex & $\begin{array}{l}\text { No. of } \\
\text { subjects }\end{array}$ & Mean & SEM & SD \\
\hline \multirow{2}{*}{ UNC } & $\mathrm{M}$ & 63 & 40.15 & 0.39 & 3.07 \\
\cline { 2 - 6 } & $\mathrm{F}$ & 103 & 35.07 & 0.24 & 2.5 \\
\hline \multirow{2}{*}{ MNC } & $\mathrm{M}$ & 63 & 40.12 & 0.35 & 2.8 \\
\cline { 2 - 6 } & $\mathrm{F}$ & 103 & 35.29 & 0.25 & 2.57 \\
\hline \multirow{2}{*}{ LNC } & $\mathrm{M}$ & 63 & 40.85 & 0.38 & 2.99 \\
\cline { 2 - 6 } & $\mathrm{F}$ & 103 & 36.01 & 0.25 & 2.56 \\
\hline \multirow{2}{*}{ MWC } & $\mathrm{M}$ & 63 & 93.87 & 1.08 & 8.55 \\
\cline { 2 - 6 } & $\mathrm{F}$ & 103 & 90.86 & 0.87 & 8.87 \\
\hline \multirow{2}{*}{ LWC } & $\mathrm{M}$ & 63 & 97.95 & 1.2 & 9.5 \\
\cline { 2 - 6 } & $\mathrm{F}$ & 103 & 97.29 & 1.05 & 10.67 \\
\cline { 2 - 6 } & $\mathrm{M}$ & 63 & 97.82 & 1.44 & 8.92 \\
\hline \multirow{2}{*}{ SEM } & $\mathrm{F}$ & 103 & 100.72 & 1.06 & 10.74 \\
\hline
\end{tabular}

SEM: standard error of mean, SD: standard deviation, UNC: upper neck circumference, MNC: middle neck circumference, LNC: lower neck circumference, UWC: upper waist circumference, MWC: middle waist circumference, LWC: lower waist circumference

Table 2: Neck and waist circumference based on sex for obese subjects.

\begin{tabular}{|l|l|l|l|l|l|}
\hline Parameter & Sex & $\begin{array}{l}\text { No. of } \\
\text { subjects }\end{array}$ & Mean & SEM & SD \\
\hline \multirow{2}{*}{ UNC } & $\mathrm{M}$ & 218 & 37.83 & 0.15 & 2.17 \\
\cline { 2 - 6 } & $\mathrm{F}$ & 173 & 33.64 & 0.17 & 2.21 \\
\hline \multirow{2}{*}{ MNC } & $\mathrm{M}$ & 218 & 37.72 & 0.14 & 2.13 \\
\cline { 2 - 6 } & $\mathrm{F}$ & 173 & 33.64 & 0.17 & 2.21 \\
\hline \multirow{2}{*}{ UNC } & $\mathrm{M}$ & 218 & 38.43 & 0.15 & 2.23 \\
\cline { 2 - 6 } & $\mathrm{F}$ & 173 & 34.71 & 0.17 & 2.17 \\
\hline \multirow{2}{*}{ MWC } & $\mathrm{M}$ & 218 & 83.69 & 0.48 & 6.34 \\
\cline { 2 - 6 } & $\mathrm{F}$ & 173 & 78.02 & 0.48 & 6.34 \\
\hline \multirow{2}{*}{ LWC } & $\mathrm{F}$ & 218 & 85.79 & 0.49 & 7.2 \\
\hline & $\mathrm{M}$ & 173 & 83.09 & 0.57 & 7.53 \\
\cline { 2 - 6 } & $\mathrm{F}$ & 173 & 86.37 & 0.43 & 6.28 \\
\hline \multirow{2}{*}{ SEM } & & & & & \\
\end{tabular}

SEM: standard error of mean, SD: standard deviation, UNC: upper neck circumference, MNC: middle neck circumference, LNC: lower neck circumference, UWC: upper waist circumference, MWC: middle waist circumference, LWC: lower waist circumference

Table 3: Statistical analysis of the neck and waist circumference in obese subjects irrespective of sex

\begin{tabular}{|c|c|c|c|c|}
\hline Parameter & $\begin{array}{l}\text { Pearson } \\
\text { value(r) }\end{array}$ & $\begin{array}{l}\text { Calculated t- } \\
\text { score for } r\end{array}$ & $\begin{array}{l}\text { Critical t-sore at } \\
0.05 \text { level }\end{array}$ & Inference \\
\hline UNC vs UWC & 0.47 & 6.84 & 1.96 & Positive correlation is weak but significant $(\mathrm{p}<0.05)$ \\
\hline MNC vs MWC & 0.29 & 3.84 & 1.96 & Positive correlation is weak but significant $(\mathrm{p}<0.05)$ \\
\hline LNC vs LWC & 0.11 & 1.41 & 1.96 & Not significant $(\mathrm{p}>0.05)$ \\
\hline UNC vs MWC & 0.36 & 4.97 & 1.96 & Positive correlation is weak but significant $(\mathrm{p}<0.05)$ \\
\hline UNC vs LWC & 0.16 & 2.08 & 1.96 & Positive correlation is weak but significant $(\mathrm{p}<0.05)$ \\
\hline MNC vs LWC & 0.13 & 1.73 & 1.96 & Not significant $(\mathrm{p}>0.05)$ \\
\hline MNC vs UWC & 0.38 & 5.23 & 1.96 & Positive correlation is weak but significant $(\mathrm{p}<0.05)$ \\
\hline LNC vs MWC & 0.24 & 3.21 & 1.96 & Positive correlation is weak but significant $(\mathrm{p}<0.05)$ \\
\hline LNC vs UWC & 0.32 & 4.27 & 1.96 & Positive correlation is weak but significant $(\mathrm{p}<0.05)$ \\
\hline
\end{tabular}


Oghenemawue et al; Anthropametric Relation of Neck and Waist Circumference

Table 4: Statistical analysis of the neck and waist circumference in overweight subjects irrespective of sex
\begin{tabular}{|l|l|l|l|l|}
\hline Parameter & $\begin{array}{l}\text { Pearson correlation } \\
\text { value(r) }\end{array}$ & $\begin{array}{l}\text { Calculated t-score for } \\
\mathbf{r}\end{array}$ & $\begin{array}{l}\text { Critical t-sore at } \\
\mathbf{0 . 0 5} \text { level }\end{array}$ & Inference \\
\hline UNC vs UWC & 0.50 & 11.2 & 1.96 & Positive correlation is weak but significant $(\mathrm{p}<0.05)$ \\
\hline MNC vs MWC & 0.11 & 7.07 & 1.96 & Positive correlation is weak but significant $(\mathrm{p}<0.05)$ \\
\hline LNC vs LWC & 0.07 & 1.41 & 1.96 & Not significant $(\mathrm{p}>0.05)$ \\
\hline UNC vs MWC & 0.39 & 8.41 & 1.96 & Positive correlation is weak but significant $(\mathrm{p}<0.05)$ \\
\hline UNC vs LWC & 0.17 & 3.31 & 1.96 & Positive correlation is weak but significant $(\mathrm{p}<0.05)$ \\
\hline MNC vs LWC & 0.12 & 2.4 & 1.96 & Positive correlation is weak but significant $(\mathrm{p}<0.05)$ \\
\hline MNC vs UWC & 0.46 & 10.15 & 1.96 & Positive correlation is weak but significant $(\mathrm{p}<0.05)$ \\
\hline LNC vs MWC & 0.25 & 5.19 & 1.96 & Positive correlation is weak but significant $(\mathrm{p}<0.05)$ \\
\hline LNC vs UWC & 0.38 & 8.13 & 1.96 & Positive correlation is weak but significant $(\mathrm{p}<0.05)$ \\
\hline
\end{tabular}

\section{Discussion}

The relationship between different parts of the body is one of the bases for predictive anthropometry and its applications in diagnosis and prosthetic designs. Our investigation revealed the correlation between the neck and waist circumference in obese individuals is very weak. No volunteer had waist circumference that is exactly twice the neck circumference. The best correlation value of 0.50 was between the upper neck circumference (UNC) and upper waist circumference (UWC) for overweight. The implication is that depending on the neck circumference to determine the waist in overweight and obese individuals may result in design of poorly fitted clothes.

There seems to be an influence in the way fat is distributed in overweight and obesity and predictive anthropometry. For example in central obesity there is accumulation of fat around the abdomen and upper body region, a situation that could lead to corresponding increase in waist circumference while in gynaecoid obesity there is accumulation of fat in hip and lower body region. These factors may affect accurate anthropometric prediction of the ratio of the neck circumference to that of the waist circumference. The assumption that the waist circumference is twice that of the neck circumference which is a common belief in the tailoring profession is therefore not applicable to overweight and obese individuals. As already noted in our earlier publication, ${ }^{[1]}$ some authors have platonically investigated this subject and have documented some reports. ${ }^{[10-13]}$ While James et al. ${ }^{[14]}$ reported a positive, strong and significant relationship between a person's waist and neck, the contrary was reported by Claire et al. ${ }^{[15]}$ The study by Ben-Noun et al, ${ }^{[16]}$ had established that the best cut off levels for neck circumference in overweight was $\geq 37 \mathrm{~cm}$ while females have it between $33.64 \mathrm{~cm}$ and $34.71 \mathrm{~cm}$. The neck circumference for obese males in our study ranges between $40.12 \mathrm{~cm}$ and $40.85 \mathrm{~cm}$ while that for females lie between $35.07 \mathrm{~cm}$ and $36.01 \mathrm{~cm}$. These findings are much similar to those of Ben Noun and associates. ${ }^{[17]}$

\section{Conclusion}

In conclusion, the waist circumference is not twice the neck circumference in overweight and obese individuals. The relationship between the neck and waist circumference is very poor in obese compared to overweight subjects. However, in both groups, the upper neck circumference and upper waist circumference have the highest correlation. Using the predictive assumption that the neck circumference is twice the waist circumference in the design of clothes for obese and overweight subjects could result in poorly fitted clothes.

\section{References}

1. Oghenemavwe LE, Asuai N. Anthropometric Relation of Neck and Waist Circumference in Non Obese: Implication for the fashion industry. Frontiers of Biomedical Science, 2016; 1(1):13-20.

2. $\mathrm{WHO}$

http://www.who.int/mediacentre/factsheets/fs311/en/retrieved July 13, 2018.

3. Alfie J, Diaz M, Olga P, Paula C, Pablo R, Guillermo F, et al. Relationship between neck and waist circumference and hypertension in the National Hypertension Registry (the RENATA study). 2012; 80(4). $\quad$ Retrieved from http://ppct.caicyt.gov.ar/index.php/rac/article/view/1488

4. Jagadamba A, Garg S, Karthiyanee K, Vinutha S. Neck circumference as an anthropometric measure of obesity in diabetics. N Am J Med Sci. 2013; 5(1): 28-31.

5. Jing-ya Z, HuiGre MZ, Li-jun W, Li C, Yao-zong T, Yu-ming C, et al. Neck circumference as an independent predictive contributor to cardio-metabolic syndrome. Cardiovascular Diabetology. 2013; 12:76.

6. Moore KL, Dalley AF, Agur AMR. Clinically oriented Anatomy, 6th ed. Baltimore: Lippincott Williams \& Wilkins. 2010; 982-992.

7. Mozaffer R, Masood A, Asghar M. Neck circumference as a useful marker of obesity: A comparison with body mass index and waist circumference. 2012. Retrieved from http://www.jpma.org.pk/full_article_text.php/article_id-3224

8. Nafiu OO, Burke C, Joyce L, Terri VL, Shobha M, Tremper KK. Neck circumference as a screening measure for identifying children with high body mass. J American Academy of Pediatrics. 2010; 126: e306.

9. Onat A, Hergene G, Yuksel H, Can G, Ayhan E, Kaya Z, et al. Neck circumference as a measure of central obesity: Association with metabolic syndrome and obstructive sleep apnea syndrome beyond waist circumference. ClinNutr. 2009; 28: 46-51.

10. Tong V, Yong J, Chen TH, Safirah N, Lin K, Min W. 'Predictor of Waist length with Neck circumference', Tira-mi-su statistic Blog, 27 December, 2009. Retrieved from http://statistic09.blogspot.com/?m=1 (Accessed 12 December 2012).

11. Roystone N, Joanne Y, Carmen L, Syafiqah J, Tan W. Relationship between neck and waist circumference. 2012. Retrieved February, 27, 2014. From http://statswelove.wordpress.com/2012/06

12. Doreen AJ, Ling JG, Wagle KK, Wen L, Stephanie YZ. Is my waist that small/ Challenging the myth: Neck=Waist? OT1103 Blog, 2 July, 2012. Retrieved from http://ismywaistthatsmall. Word press.com/ about (Accessed 16 September 2013)

13. Cindy K. Neck Size in Relation to Waist Size. Retrieved from http://healthyliving.azcentral.com/neck-size-relation-waist-size14393.html (Accessed 18 September 2013)

14. James WW, Wei M, Max K. 'Measure Neck to get Waist sizeMyth or Reality?' 27 June. Retrieved from http://waistvsneck.blogspot.com/2011/06/home.html?m=1 (Accessed 18 September 2013).

15. Claire, Huimin, Marilyn, Moka, Siew Jing. Neck-waist ratio, Is it 


\section{Oghenemawae et al; Anthropametric Relation of Neck and Waist Circumference}

true? 6 July, $2010 . \quad$ Retrieved from

http://neckandwaist.blogspot.com/.Blog PT0903

16. Ben-Noun L, Sohar E, Laor A. Neck circumference as a simple screening measure for identifying overweight and obese patients.
Obese Res. 2001; 9:470-7.

17. Ben-Noun L, Sohar E, Laor A. Relationship of neck circumference to cardiovascular risk factors. Obese Res. 2003; 11: 226-31.

Copyright: (C) the author(s), publisher. Academia Anatomica International is an Official Publication of "Society for Health Care \& Research Development". It is an open-access article distributed under the terms of the Creative Commons Attribution Non-Commercial License, which permits unrestricted non-commercial use, distribution, and reproduction in any medium, provided the original work is properly cited.

How to cite this article: Oghenemavwe LE, Orupabo CSD, Onisoman ZO. Anthropometric Relation of Neck and Waist Circumference in Overweight and Obese Nigerian Subjects: Implication for the Fashion Industry. Acad. Anat. Int. 2019;5(1):96-99.

DOI: dx.doi.org/10.21276/aanat.2019.5.1.23 